\title{
Thrombus in Catheter
}

National Cancer Institute

\section{Source}

National Cancer Institute. Thrombus in Catheter. NCI Thesaurus. Code C78638.

The development of a blood clot in a catheter. 